\title{
Metabolic clustering of risk factors: evaluation of Triglyceride-glucose index (TyG index) for evaluation of insulin resistance
}

Sikandar Hayat Khan ${ }^{1 *} \mathbb{0}$, Farah Sobia ${ }^{2}$, Najmusaqib Khan Niazi ${ }^{3}$, Syed Mohsin Manzoor ${ }^{1}$, Nadeem Fazal ${ }^{4}$ and Fowad Ahmad ${ }^{4}$

\begin{abstract}
Background: Metabolic syndrome over the years have structured definitions to classify an individual with the disease. Literature review suggests insulin résistance is hallmark of these metabolic clustering. While measuring insulin resistance directly or indirectly remains technically difficult in general practice, along with multiple stability issues for insulin, various indirect measures have been suggested by authorities. Fasting triglycerides-glucose (TyG) index is one such marker, which is recently been suggested as a useful diagnostic marker to predict metabolic syndrome. However, limited data is available on the subject with almost no literature from our region on the subject.
\end{abstract}

Objective: 1. To correlate TyG index with insulin resistance, anthropometric indices, small dense LDLc, HbA1c and nephropathy. 2. To evaluate TyG index as a marker to diagnose metabolic syndrome in comparison to other available markers.

Design-cross-sectional analysis: Place and duration of study-From Jun-2016 to July-2017 at PSS HAFEEZ hospital Islamabad.

Subjects and methods: From a finally selected sample size of 227 male and female subjects we evaluated their anthropometric data, $\mathrm{HbA} 1 \mathrm{c}$, lipid profile including calculated sdLDLc, urine albumin creatinine raito(UACR) and insulin resistance (HOMAIR). TyG index was calculated using formula of Simental-Mendía LE et al. Aforementioned parameters were correlated with TyG index, differences between subjects with and without metabolic syndrome were calculated using Independent sample t-test. Finally ROC curve analysis was carried out to measure AUC for candidate parameters including TyG Index for comparison.

Results: TyG index in comparison to other markers like fasting triglycerides, HOMAIR, HDLc and non-HDLc demonstrated higher positive linear correlation with BMI, atherogenic dyslipidemia (sdLDLc), nephropathy (UACR), HbA1c and insulin resistance. TyG index showed significant differences between various markers among subjects with and without metabolic syndrome as per IDF criteria. AUC (Area Under Curve) demonstrated highest AUC for TyG as [(0.764, $95 \% \mathrm{Cl} 0.700-0.828, \mathrm{p}$-value $\leq 0.001)]$ followed by fasting triglycerides $[(0.724,95 \% \mathrm{Cl} 0.656-0.791, \mathrm{p}$-value $\leq 0.001)]$, sdLDLc $[(0.695,95 \% \mathrm{Cl} 0.626-0.763$, p-value $\leq 0.001)]$, fasting plasma glucose $[(0.686,95 \% \mathrm{Cl} 0.616-0.756$, p-value $\leq 0.001)]$, Non-HDLc $[(0.640,95 \% \mathrm{Cl} 0.626-0.763$, p-value $\leq 0.001)]$ and HOMAIR $[(0.619,95 \% \mathrm{Cl} 0.545-0.694$, p-value $\leq 0.001)]$.

Conclusion: TyG index, having the highest AUC in comparison to fasting glucose, triglycerides, sdLDLC, non-HDLC and HOMAIR can act as better marker for diagnosing metabolic syndrome.

\footnotetext{
*Correspondence: sik_cpsp@yahoo.com

${ }^{1}$ Department of Pathology, PNS HAFEEZ, Islamabad, Pakistan

Full list of author information is available at the end of the article
} 


\section{Background}

Cardiovascular disease (CVD), non-alcohalic fatty liver disease (NAFLD)/Non-alcohalic Steato-hepatitis (NASH) and polycystic ovarian syndrome (PCOS) lead to enormous burden in morbidity and mortality along with effects on health economics. "Common soil hypothesis" suggests the singular entity to be responsible for most of these disorders, and that is resistance to insulin action [1]. Insulin resistance syndrome result in inability of insulin to exert their effects at target issues thus cause appearance of various abnormality spanning from NAFLD, NASH, PCOS to CVD [2]. Therefore, knowledge about insulin resistance in these subjects seems instrumental in identifying diagnosis and further on the management strategy [3]. Various direct and indirect measures to estimate insulin have been proposed starting from euglycemic clamp test to surrogate markers like QUICKI, HOMAIR and Matsuda Index [4]. However, in clinical practice at the primary care level it's not only difficult to measure due to cost-effects but also stability of the insulin in blood becomes a question mark [5]. Thus the primary care physician needs a simple, robust and available marker as a surrogate for insulin resistance to address this very common pathology.

Recent evidence has suggested that calculated measure incorporating triglyceride and glucose, termed "Fasting triglyceride-glucose index" or simply "TyG index" has been suggested to help as surrogate marker for insulin resistance. Initial studies by Simental-Mendía et al. and Abbasi et al. $[6,7]$ have demonstrated their utility as a more tangible marker for metabolic syndrome and underlying insulin resistance. This measure only involves simple lab parameters like triglycerides and glucose, which can be measured without much effort or cost. Additionally, the parameter has even been shown to predict insulin resistance in a better manner than surrogate markers like HOMAIR once compared with direct measure like hyperglycemic clamp method [8]. Apart from metabolic syndrome, knowing its effect on nephropathy and atherogenic dyslipidemia will be interesting, as metabolic syndrome does not specifically include these parameters into its conventional definition. Moreover, relation between raised ALT levels and TyG index also needs to be evaluated, as Simental-Mendía [9] has also shown TyG index as a possible marker for diagnosing NASH among female subjects. Finally, multiple studies within our country have shown have evaluated metabolic syndrome and insulin resistance, the search on PakMediNet.com did not yield any study evaluating TyG index among our population cohort.

In the light of the promise as shown by few studies on TyG index to diagnose metabolic syndrome and its association with insulin resistance we decided to evaluate the performance of TyG index with insulin resistance, atherogenic dyslipidemia, anthropometric indices and urine albumin creatinine ratio. Furthermore, we also want to measure the performance of TyG index in diagnosing metabolic syndrome in comparison to insulin resistance and certain other anthropometric and lipid and non-lipid biomarkers.

\section{Methods}

This comparative cross-sectional analysis was carried out from April-2016 to July-2017 at the department of pathology and department of medicine, PNS HAFEEZ Hospital (Islamabad, Pakistan). Formal approval was taken from the hospital ethical review committee regarding the study project before the start of study. Based upon non-probability convenience sampling and targeting patients who reported to us in "exact medical fasting status" we invited them to participate in the study. The subjects who volunteer were further evaluated for the presence of chronic disorders, exactness of medical fasting and taking anti-diabetic or anti-hypertensive drugs which could confound our results, pregnancy, any acute medical or surgical conditions and age $<18$ years. Presence of these conditions implied exclusion from enrollment into study. Finally selected individuals $(n=228)$. Sample size was calculated based upon http://www.raoso $\mathrm{ft} . \mathrm{com} /$ samplesize.html.

Male subjects who had an initial raised level of total cholesterol were invited to the study. Subjects who had diabetes, hypertension, ischemic heart disease, age $<18$ years or having any other chronic or acute ailments, taking any routine medication were excluded from the study. Those who initially consented verbally were requested to come to pathology department in "exact medical fasting status". After a brief questionnaire based clinical history, subjects were evaluated for anthropometric indices and blood pressure. Anthropometric indices including height, weight, waist and hip circumference were calculated as per WHO criteria available at: http://www.who.int/childgrowth/publications/physi cal_status/en/. Following that blood specimens were collected in following tubes as Na-Fluoride, EDTA and plain bottles for evaluation of glucose, lipid profile, insulin, ALT and HbA1c. Urine specimen were collected in 171 subjects for urine albumin creatinine ratio (UACR) which is considered as a surrogate marker for nephropathy [10]. Glucose, total cholesterol, triglycerides and ALT were measured on Selectra-ProM random access clinical chemistry analyzer by following methods: GOD-PAP method, CHOD-PAP method, GPO-PAP, IFCC recommended kinetic method at $37^{\circ} \mathrm{C}$. We measured serum HDLc and LDLc by cholesterol esterase method on AVIDA-1800 (Clinical chemistry system). HbA1c was 
analyzed by ion exchange resin chromatography, while insulin on serum was measured by chemiluminescence technique on Immulite ${ }^{\circledR} 1000$. AVIDA-1800 was also utilized to measure UACR. HOMAIR, TyG index and small density LDL-cholesterol (sdLDLc) were calculated vide given references [6,11, 12].

We lost following samples during processing either due hemolysis or quantity was not sufficient for analysis as patient never appear for a re-test as: 2 for HDLc, LDLc and 4 for $\mathrm{HbA} 1 \mathrm{c}$ and insulin.

\section{Data analysis}

Patient data was initially entered into Excel work sheath and later moved to SPSS. Descriptive statistics for subjects were calculated using SPSS descriptive statistics. Parameters like waist to height ratio, BMI, waist to height ratio, fasting triglycerides, HDLc, TyG index, uric acid, non-HDLc and HbA1c were compared for gender differences by Independent sample t-test. Pearson correlation was used to correlate fasting triglycerides, HDLc, TyG and HOMAIR with various anthropometric indices and biochemical parameters. The differences among subjects having IDF-defined metabolic syndrome and otherwise for various end-points were measured using independent sample t-test. ROC curve analysis was utilized with presence or absence of metabolic syndrome as per IDF defined criteria to compare area under the curve (AUC) for candidate metabolic syndrome markers including fasting plasma glucose, triglycerides, non-HDLc, sdLDLc, HOMAIR and TyG index.

\section{Results}

We had a total of 227 subjects in our sample with 118 females and rest males. Details of data on age, anthropometric and biochemical measures from our study population are shown in Table 1. Few parameters including BMI, waist to height ratio, fasting triglycerides, TyG index, HDLc, uric acid, non-HDLc, HbA1c were significantly different between male and female subjects (Table 2). TyG in comparison to other markers like fasting triglycerides, HOMAIR, HDLc and non-HDLc was the only marker which showed higher or near equivalent linear correlation with multiple BMI and other biochemical parameters including atherogenic dyslipidemia surrogate sdLDLC, nephropathy, glycated hemoglobin and insulin resistance as depicted in Table 3. Differences between various markers among subjects with and without metabolic syndrome as per IDF criteria are shown in Table 4. In order to evaluate diagnostic efficiency by measuring AUC (Area Under Curve) for TyG and other potential markers including fasting triglycerides, fasting plasma glucose, HOMAIR, sdLDLc and Non-HDLc we observed highest AUC for TyG as [(0.764, 95\% CI 0.700-0.828, p-value $\leq 0.001)$ ] followed by fasting triglycerides $[(0.724,95 \%$ CI $0.656-0.791, \mathrm{p}$-value $\leq 0.001)]$, sdLDLc $[(0.695,95 \% \mathrm{CI}$ $0.626-0.763, \mathrm{p}$-value $\leq 0.001)$ ], fasting plasma glucose $[(0.686,95 \%$ CI $0.616-0.756$, p-value $\leq 0.001)]$, NonHDLc [(0.640, 95\% CI $0.626-0.763$, p-value $\leq 0.001)]$ and HOMAIR $[(0.619,95 \%$ CI $0.545-0.694$, p-value $\leq 0.001)]$ (Fig. 1).

Table 1 Descriptive statistics of age, anthropometric and biochemical measures in our data set

\begin{tabular}{|c|c|c|c|c|c|}
\hline \multirow[t]{2}{*}{ Parameters } & \multirow[t]{2}{*}{$\mathbf{N}$} & \multirow[t]{2}{*}{ Mean } & \multirow[t]{2}{*}{ Std. dev } & \multicolumn{2}{|l|}{ Kurtosis } \\
\hline & & & & Statistic & Std. error \\
\hline Age (years) & 227 & 46.37 & 11.98 & 0.553 & 0.322 \\
\hline Body mass index (BMI) & 227 & 27.10 & 5.24 & 1.970 & 0.322 \\
\hline Waist to hip ratio (WHpR) & 227 & 0.93 & 0.08 & 70.77 & 0.322 \\
\hline Waist to height ratio (WHtR) & 227 & 0.57 & 0.07 & -0.076 & 0.322 \\
\hline Fasting plasma glucose (mmol/L) & 227 & 5.51 & 1.93 & 22.427 & 0.322 \\
\hline Total cholesterol (mmol/L) & 227 & 4.47 & 0.61 & 0.563 & 0.322 \\
\hline Fasting triglycerides (mmol/L) & 227 & 1.58 & 0.71 & 3.934 & 0.322 \\
\hline $\mathrm{HDLC}(\mathrm{mmol} / \mathrm{L})$ & 225 & 0.98 & 0.26 & 10.105 & 0.323 \\
\hline LDLc (mmol/L) & 225 & 2.69 & 0.73 & -0.296 & 0.323 \\
\hline Non-HDLc (mmol/L) & 227 & 3.50 & 0.64 & 0.492 & 0.322 \\
\hline Uric acid (mmol/L) & 226 & 302.67 & 79.14 & 1.78 & 0.322 \\
\hline $\mathrm{HbA1c}(\%)$ & 223 & 5.73 & 0.93 & 3.04 & 0.324 \\
\hline HOMAIR & 223 & 2.32 & 1.83 & 10.06 & 0.324 \\
\hline Urine albumin creatinine ratio & 171 & 2.76 & 4.94 & 75.16 & 0.379 \\
\hline
\end{tabular}


Table 2 Gender associated differences in age, anthropometric and biochemical measures in our sample population

\begin{tabular}{|c|c|c|c|c|c|}
\hline Parameters & Gender & $\mathbf{N}$ & Mean & Std. Dev & Sig. (2-tailed) \\
\hline \multirow[t]{2}{*}{ Age (years) } & Male & 109 & 47.94 & 11.35 & 0.058 \\
\hline & Female & 118 & 44.92 & 12.41 & \\
\hline \multirow[t]{2}{*}{ Body mass index (BMI) } & Male & 109 & 25.96 & 4.85 & 0.002 \\
\hline & Female & 118 & 28.15 & 5.39 & \\
\hline \multirow[t]{2}{*}{ Waist to hip ratio (WHpR) } & Male & 109 & 0.93 & 0.10 & 0.223 \\
\hline & Female & 118 & 0.94 & 0.06 & \\
\hline \multirow[t]{2}{*}{ Waist to height ratio (WHtR) } & Male & 109 & 0.55 & 0.06 & $<0.001$ \\
\hline & Female & 118 & 0.60 & 0.07 & \\
\hline \multirow[t]{2}{*}{ Fasting plasma glucose (mmol/L) } & Male & 109 & 5.71 & 2.12 & 0.138 \\
\hline & Female & 118 & 5.33 & 1.74 & \\
\hline \multirow[t]{2}{*}{ Total cholesterol (mmol/L) } & Male & 109 & 4.54 & 0.59 & 0.111 \\
\hline & Female & 118 & 4.41 & 0.61 & \\
\hline \multirow[t]{2}{*}{ Fasting triglycerides (mmol/L) } & Male & 109 & 1.68 & 0.82 & 0.044 \\
\hline & Female & 118 & 1.49 & 0.59 & \\
\hline \multirow[t]{2}{*}{ Triglyceride-glucose index (TyG) } & Male & 109 & 8.80 & 0.58 & 0.030 \\
\hline & Female & 118 & 8.65 & 0.46 & \\
\hline \multirow[t]{2}{*}{$\mathrm{HDLC}(\mathrm{mmol} / \mathrm{L})$} & Male & 108 & 0.91 & 0.21 & $<0.001$ \\
\hline & Female & 117 & 1.04 & 0.28 & \\
\hline \multirow[t]{2}{*}{ LDLc (mmol/L) } & Male & 107 & 2.71 & 0.68 & 0.624 \\
\hline & Female & 118 & 2.66 & 0.77 & \\
\hline \multirow[t]{2}{*}{ Non-HDLc (mmol/L) } & Male & 109 & 3.63 & 0.58 & 0.004 \\
\hline & Female & 118 & 3.39 & 0.68 & \\
\hline \multirow[t]{2}{*}{ Uric acid (mmol/L) } & Male & 108 & 330.36 & 81.61 & $<0.001$ \\
\hline & Female & 118 & 277.33 & 67.79 & \\
\hline \multirow[t]{2}{*}{ HbA1c (\%) } & Male & 107 & 5.57 & 0.96 & 0.010 \\
\hline & Female & 116 & 5.89 & 0.88 & \\
\hline \multirow[t]{2}{*}{ HOMAIR } & Male & 107 & 2.28 & 1.96 & 0.707 \\
\hline & Female & 116 & 2.37 & 1.70 & \\
\hline \multirow[t]{2}{*}{ UACR } & Male & 75 & 2.31 & 2.47 & 0.292 \\
\hline & Female & 96 & 3.11 & 6.21 & \\
\hline
\end{tabular}

\section{Discussion}

Our study highlighted that TyG index is the most efficient marker to diagnose metabolic syndrome. This finding is in accordance with the work of Simental-Mendía et al. and Abbasi et al. [6, 7]. Apart from the diagnosis of metabolic syndrome, we also observed a relatively better comparative linear correlation between TyG index and other cardiovascular (CVD) risk biomarkers for atherogenic dyslipidemia, nephropathy, underlying insulin resistance and hemoglobin glycation. The later finding further enhance the significance of TyG index as a "pan CVD risk marker". The support from "TyG as a pan CVD marker" comes from studies carried out to link angiographic based risk findings in coronary artery disease (CAD) like obstructive CAD and coronary artery calcium scores were found to be more associated with TyG index and identified TyG as independent risk marker for CAD [13]. Similar studies from Korea have also identified the independent nature of TyG for depicting underlying cardiovascular diseases [14, 15]. Provided it's independent nature as depicted by the aforementioned evidence shared, we could not find data linking TyG with small dense LDLc and nephropathy. So this area needs to be evaluated further.

Most data including our earlier work on the subject have shown HOMAIR as a very significant predictor of metabolic syndrome [16-18]. However, here we observed HOMAIR to show the least AUC in comparison to other evaluated markers. Probable explanations could be: Firstly, we believe that HOMAIR being the product of fasting insulin and glucose based upon a physiological mathematical modelling could depict risk related to insulin signaling pathway defects and may not be actually influencing risks resulting from hepatocyte function or alterations resulting from polygenic modes of causation of cardiovascular diseases [19, 20]. Secondly, 
Table 3 Correlation between fasting triglycerides, TyG, HDLC and HOMAIR with anthropometric indices and biochemical risks

\begin{tabular}{|c|c|c|c|c|c|c|}
\hline Parameter & & $\begin{array}{l}\text { Fasting } \\
\text { triglyceride(mmol/L) }\end{array}$ & $\begin{array}{l}\text { (Glucose- } \\
\text { triglyceride } \\
\text { index) TyG }\end{array}$ & $\mathrm{HDLc}(\mathrm{mmol} / \mathrm{L})$ & $\begin{array}{l}\text { Non-HDLc } \\
\text { (mmol/L) }\end{array}$ & HOMAIR \\
\hline \multirow[t]{3}{*}{ WHpR } & Pearson correlation & $0.154^{*}$ & $0.167^{*}$ & 0.002 & $0.178^{* *}$ & 0.100 \\
\hline & Sig. (2-tailed) & 0.020 & 0.012 & 0.974 & 0.007 & 0.136 \\
\hline & N & 227 & 227 & 225 & 227 & 223 \\
\hline \multirow[t]{3}{*}{ Fasting plasma glucose (mmol/L) } & Pearson correlation & $0.190^{* *}$ & $0.571^{* *}$ & -0.066 & 0.030 & $0.398^{* *}$ \\
\hline & Sig. (2-tailed) & 0.004 & $<0.001$ & 0.325 & 0.653 & $<0.001$ \\
\hline & $\mathrm{N}$ & 227 & 227 & 225 & 227 & 223 \\
\hline \multirow[t]{3}{*}{ Total cholesterol (mmol/L) } & Pearson correlation & $0.445^{* *}$ & $0.385^{* *}$ & 0.105 & $0.887^{* *}$ & -0.013 \\
\hline & Sig. (2-tailed) & $<0.001$ & $<0.001$ & 0.117 & $<0.001$ & 0.842 \\
\hline & N & 227 & 227 & 225 & 227 & 223 \\
\hline \multirow[t]{3}{*}{ TyG } & Pearson correlation & $0.869^{* *}$ & 1 & $-0.290^{* *}$ & $0.460^{* *}$ & $0.274^{* *}$ \\
\hline & Sig. (2-tailed) & $<0.001$ & - & $<0.001$ & $<0.001$ & $<0.001$ \\
\hline & $\mathrm{N}$ & 227 & 227 & 225 & 227 & 223 \\
\hline \multirow[t]{3}{*}{ LDLc (mmol/L) } & Pearson correlation & 0.003 & 0.069 & -0.005 & $0.381^{* *}$ & 0.025 \\
\hline & Sig. (2-tailed) & 0.970 & 0.302 & 0.941 & $<0.001$ & 0.715 \\
\hline & $\mathrm{N}$ & 225 & 225 & 224 & 225 & 222 \\
\hline \multirow[t]{3}{*}{ sdLDL (mmol/L) } & Pearson correlation & $0.540^{* *}$ & $0.526^{* *}$ & $-0.133^{*}$ & $0.353^{* *}$ & 0.085 \\
\hline & Sig. (2-tailed) & $<0.001$ & $<0.001$ & 0.046 & $<0.001$ & 0.206 \\
\hline & $\mathrm{N}$ & 227 & 227 & 225 & 227 & 223 \\
\hline \multirow[t]{3}{*}{$\mathrm{HbA1c}(\%)$} & Pearson correlation & 0.007 & $0.240^{* *}$ & 0.058 & -0.087 & $0.193^{* *}$ \\
\hline & Sig. (2-tailed) & 0.915 & $<0.001$ & 0.387 & 0.784 & 0.004 \\
\hline & $\mathrm{N}$ & 223 & 223 & 222 & 221 & 223 \\
\hline \multirow[t]{3}{*}{ UACR } & Pearson correlation & 0.119 & $0.199^{* *}$ & -0.080 & 0.100 & -0.017 \\
\hline & Sig. (2-tailed) & 0.122 & 0.009 & 0.298 & 0.196 & 0.827 \\
\hline & $\mathrm{N}$ & 171 & 171 & 170 & 170 & 171 \\
\hline
\end{tabular}

*significant at $<0.05$

**significant at $<0.01$

Table 4 Differences of various biomarkers in subjects with and without metabolic syndrome as per IDF criteria

\begin{tabular}{|c|c|c|c|c|c|}
\hline Parameter & Metabolic syndrome & $\mathbf{N}$ & Mean & Std. dev & Sig. (2-tailed) \\
\hline \multirow[t]{2}{*}{ Fasting plasma glucose (mmol/L) } & Present & 117 & 5.72 & 1.85 & 0.070 \\
\hline & Absent & 108 & 5.25 & 1.98 & \\
\hline \multirow[t]{2}{*}{ Fasting triglyceride (mmol/L) } & Present & 117 & 1.79 & 0.68 & $<0.001$ \\
\hline & Absent & 108 & 1.37 & 0.68 & \\
\hline \multirow[t]{2}{*}{ Triglyceride-glucose index (TyG) } & Present & 117 & 8.91 & 0.42 & $<0.001$ \\
\hline & Absent & 108 & 8.53 & 0.55 & \\
\hline \multirow[t]{2}{*}{$\mathrm{HDLC}(\mathrm{mmol} / \mathrm{L})$} & Present & 117 & 0.94 & 0.25 & 0.040 \\
\hline & Absent & 108 & 1.02 & 0.26 & \\
\hline \multirow[t]{2}{*}{ Non-HDLc (mmol/L) } & Present & 117 & 3.61 & 0.60 & 0.004 \\
\hline & Absent & 108 & 3.36 & 0.65 & \\
\hline \multirow[t]{2}{*}{$\mathrm{sdLDLc}(\mathrm{mmol} / \mathrm{L})$} & Present & 117 & 0.92 & 0.33 & $<0.001$ \\
\hline & Absent & 108 & 0.70 & 0.29 & \\
\hline \multirow[t]{2}{*}{ HbA1c (\%) } & Present & 115 & 5.93 & 0.94 & 0.001 \\
\hline & Absent & 107 & 5.51 & 0.88 & \\
\hline \multirow[t]{2}{*}{ HOMAIR } & Present & 115 & 2.53 & 1.77 & 0.084 \\
\hline & Absent & 107 & 2.10 & 1.89 & \\
\hline
\end{tabular}




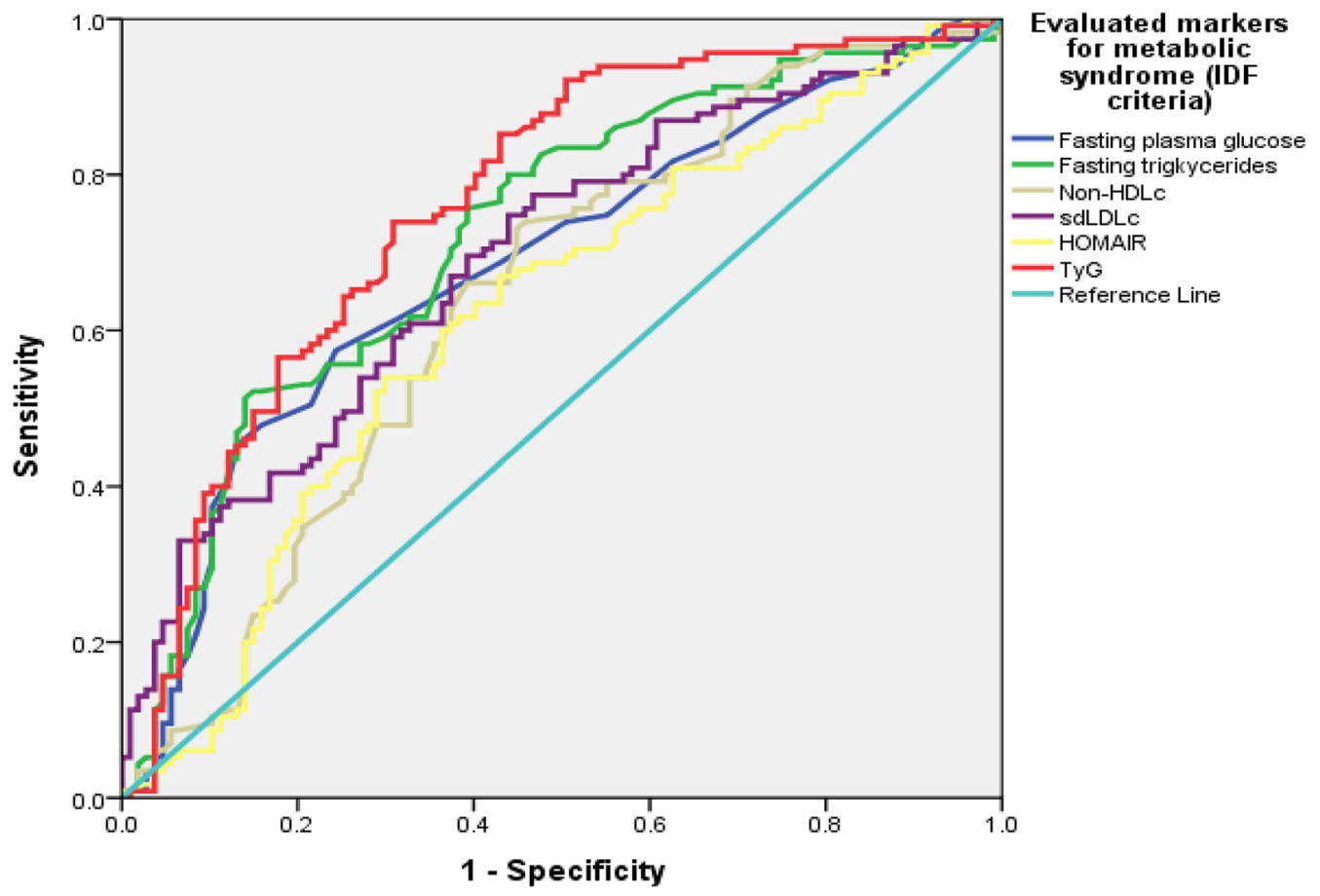

Fig. 1 ROC curve analysis for predicting evaluated markers AUC against a diagnosis of metabolic syndrome as per IDF criteria. $(n=227)$

HOMA model has inherent weakness and it may not be applicable to all patient groups like lean patients with metabolic risks, which is a common category in Asian population as highlighted by Kang et al. [21]. Available evidence review also suggests differential outcomes from two insulin resistance related measure HOMAIR, where the first version, the tradition one as utilized by us i.e., $\mathrm{HOMA}_{1}$ within our study and another one suggested by Levy et al. based upon a computer program being called $\mathrm{HOMA}_{2}[22,23]$. The latter version, by some authorities have been qualified as better version for Asian population [24]. However, we feel that more data on differences be two between the two equations is needed to validate our findings. Lastly, evidence from literature in certain specific patient groups suggests limited role of HOMAIR with associated cardiovascular disease mortality [25]. Similarly, evidence highlights that are racial and ethnic differences among human subjects with regards to insulin resistance, and type-2 diabetes mellitus [26-28].

We feel certain limitations to our study needs to be acknowledged: Firstly, our cross-sectional design in design which has inherent limitations. Furthermore, we feel more studies with a much larger sample size by clinical epidemiologists to conclude the real yield of this tests.

Provided the limitations we mentioned, we believe the study remains clinically valid as it provides a very simple mathematical marker for clinical use which is not only cost-effective but also be useful in small set ups with minimal laboratory facilities. Moreover, further augmentation of this biomarker any large-scale studies can help replace the varying definitions of metabolic syndrome which are sometimes creating diagnostic confusion and makes thing complex than easy in primary clinics.

\section{Conclusion}

TyG index, having the highest AUC in comparison to fasting glucose, triglycerides, sdLDLc, non-HDLc and HOMAIR can act as better marker for diagnosing metabolic syndrome. Keeping in view the simplicity of marker, cost-effectiveness and feasibility at small-scale lab and being depictive of other cardiovascular risks it is suggested to incorporate this test in clinical use.

\section{Abbreviations}

TyG index: triglyceride-glucose index; IDF: International Diabetic Federation; GPO-PAP: glucose peroxidase method; ROC: receiver operating curve; UACR : urine albumin creatinine ratio; sdLDLc: small dense LDL cholesterol; WHpR: waist to hip ratio.

\section{Authors' contributions}

SHK: Idea, sampling, lab testing, stats and data analysis and medical writing, discussion and conclusion, FS and NKN: Sampling, writing, discussion and conclusion, SMM: Sampling, lab testing, stats and data analysis, NF: Statistical analysis, data analysis, FA: Data analysis, discussion and medical writing. All authors read and approved the final manuscript. 


\section{Author details}

${ }^{1}$ Department of Pathology, PNS HAFEEZ, Islamabad, Pakistan. ${ }^{2}$ CMH Multan, Lahore, Pakistan. ${ }^{3}$ Healthcare Administration, Islamabad, Pakistan. ${ }^{4}$ Department of Medicine, PNS HAFEEZ, Islamabad, Pakistan.

\section{Acknowledgements}

The authors acknowledge the work of lab technician Mazhar, Lab technician Miss Huma for the support and help.

\section{Competing interests}

The authors declare that they have no competing interests.

\section{Availability of data and materials}

SPSS data spread sheet and SPSS data outputs are available for review from corresponding author, if requested.

\section{Consent for publication}

Not applicable (No individual data was presented).

\section{Data funding}

The study had no funding source to disclose.

\section{Ethics approval and consent to participate}

The project "Gestational diabetes mellitus" was approved by PNS HAFEEZ hospital's ethical review committee. All subjects signed informed consent form after they were explained in detail regarding study project.

\section{Publisher's Note}

Springer Nature remains neutral with regard to jurisdictional claims in published maps and institutional affiliations.

Received: 16 August 2018 Accepted: 24 September 2018

Published online: 05 October 2018

\section{References}

1. Ceriello A, Motz E. Is oxidative stress the pathogenic mechanism underlying insulin resistance, diabetes, and cardiovascular disease? The common soil hypothesis revisited. Arterioscler Thromb Vasc Biol. 2004;24(5):816-23.

2. Kelley CE, Brown AJ, Diehl AM, Setji TL. Review of nonalcoholic fatty liver disease in women with polycystic ovary syndrome. World $J$ Gastroenterol. 2014;20(39):14172-84. https://doi.org/10.3748/wjg.v20. i39.14172.

3. Macut D, Božić-Antić I, Bjekić-Macut J, Tziomalos K. Management of endocrine disease: polycystic ovary syndrome and nonalcoholic fatty liver disease. Eur J Endocrinol. 2017;177(3):R145-58. https://doi. org/10.1530/EJE-16-1063.

4. Muniyappa R, Madan R, Quon MJ. Assessing insulin sensitivity and resistance in humans. In: De Groot $L J$, Chrousos G, Dungan K, Feingold KR, Grossman A, Hershman JM, et al. editors. Endotext [Internet]. South Dartmouth (MA): MDText.com, Inc.; 2000-2015.

5. Oddoze C, Lombard E, Portugal $H$. Stability study of 81 analytes in human whole blood, in serum and in plasma. Clin Biochem. 2012;45(6):464-9. https://doi.org/10.1016/j.clinbiochem.2012.01.012.

6. Simental-Mendía LE, Rodríguez-Morán M, Guerrero-Romero F. The product of fasting glucose and triglycerides as surrogate for identifying insulin resistance in apparently healthy subjects. Metab Syndr Relat Disord. 2008;6(4):299-304. https://doi.org/10.1089/met.2008.0034.

7. Abbasi F, Reaven GM. Comparison of two methods using plasma triglyceride concentration as a surrogate estimate of insulin action in nondiabetic subjects: triglycerides $\times$ glucose versus triglyceride/highdensity lipoprotein cholesterol. Metabolism. 2011;60(12):1673-6. https ://doi.org/10.1016/j.metabol.2011.04.006

8. Vasques AC, Novaes FS, de Oliveira Mda S, Souza JR, Yamanaka A Pareja JC, et al. TyG index performs better than HOMA in a Brazilian population: a hyperglycemic clamp validated study. Diabetes Res Clin Pract. 2011;93(3):e98-100. https://doi.org/10.1016/j.diabr es.2011.05.030.

9. Simental-Mendía LE, Simental-Mendía E, Rodríguez-Hernández H, Rodríguez-Morán M, Guerrero-Romero F. The product of triglycerides and glucose as biomarker for screening simple steatosis and NASH in asymptomatic women. Ann Hepatol. 2016;15(5):715-20. https://doi. org/10.5604/16652681.1212431.

10. Bakker AJ. Detection of microalbuminuria. Receiver operating characteristic curve analysis favors albumin-to-creatinine ratio over albumin concentration. Diabetes Care. 1999;22(2):307-13.

11. Matthews DR, Hosker JP, Rudenski AS, Naylor BA, Treacher DF, Turner RC. Homeostasis model assessment: insulin resistance and beta-cell function from fasting plasma glucose and insulin concentrations in man. Diabetologia. 1985;28(7):412-9.

12. Srisawasdi P, Chaloeysup S, Teerajetgul Y, Pocathikorn A, Sukasem C, Vanavanan S, et al. Estimation of plasma small dense LDL cholesterol from classic lipid measures. Am J Clin Pathol. 2011;136(1):20-9. https:// doi.org/10.1309/AJCPLHJBGG9L3ILS.

13. Won KB, Kim YS, Lee BK, Heo R, Han D, Lee JH, et al. The relationship of insulin resistance estimated by triglyceride glucose index and coronary plaque characteristics. Medicine (Baltimore). 2018;97(21):e10726. https ://doi.org/10.1097/MD.0000000000010726.

14. Lee SB, Ahn CW, Lee BK, Kang S, Nam JS, You JH, et al. Association between triglyceride glucose index and arterial stiffness in Korean adults. Cardiovasc Diabetol. 2018;17(1):41. https://doi.org/10.1186/ s12933-018-0692-1.

15. Kim MK, Ahn CW, Kang S, Nam JS, Kim KR, Park JS. Relationship between the triglyceride glucose index and coronary artery calcification in Korean adults. Cardiovasc Diabetol. 2017;16(1):108. https://doi. org/10.1186/s12933-017-0589-4

16. Płaczkowska S, Pawlik-Sobecka L, Kokot I, Piwowar A. Estimation of metabolic factors related to insulin resistance and metabolic syndrome in young people. Scand J Clin Lab Invest. 2018;9:1-8. https://doi. org/10.1080/00365513.2018.1469787.

17. Yin J, Li M, Xu L, Wang Y, Cheng H, Zhao X, Mi J. Insulin resistance determined by Homeostasis Model Assessment (HOMA) and associations with metabolic syndrome among Chinese children and teenagers. Diabetol Metab Syndr. 2013;5(1):71. https://doi. org/10.1186/1758-5996-5-71.

18. Pansuria $M, X i H$, Li L, Yang XF, Wang H. Insulin resistance, metabolic stress, and atherosclerosis. Front Biosci (Schol Ed). 2012;1(4):916-31.

19. van Houwelingen $\mathrm{HC}$. The future of biostatistics: expecting the unexpected. Stat Med. 1997;16(24):2773-84.

20. Wallace TM, Levy JC, Matthews DR. Use and abuse of HOMA modeling. Diabetes Care. 2004;27(6):1487-95.

21. Kang ES, Yun YS, Park SW, Kim HJ, Ahn CW, Song YD, et al. Limitation of the validity of the homeostasis model assessment as an index of insulin resistance in Korea. Metabolism. 2005;54(2):206-11.

22. Levy JC, Matthews DR, Hermans MP. Correct homeostasis model assessment (HOMA) evaluation uses the computer program. Diabetes Care. 1998;21(12):2191-2.

23. Geloneze B, Vasques AC, Stabe CF, Pareja JC, Rosado LE, Queiroz EC. Tambascia MA; BRAMS Investigators. HOMA1-IR and HOMA2-IR indexes in identifying insulin resistance and metabolic syndrome: Brazilian Metabolic Syndrome Study (BRAMS). Arq Bras Endocrinol Metabol. 2009;53(2):281-7

24. Song YS, Hwang YC, Ahn HY, Park CY. Comparison of the usefulness of the updated homeostasis model assessment (HOMA2) with the original HOMA1 in the prediction of type 2 diabetes mellitus in Koreans. Diabetes Metab J. 2016;40(4):318-25. https://doi.org/10.4093/ dmj.2016.40.4.318.

25. Sánchez-Villanueva R, Estrada P, del Peso G, Grande C, Díez JJ, Iglesias P, Grupo de Estudios Peritoneales de Madrid de REDINREN (Red Renal de Investigación de la RETICS 06/0016, del Instituto de Salud Carlos III); del IRSIN (Instituto Reina Sofía de Investigación Nefrológica), et al. Repeated analysis of estimated insulin resistance using the HOMAIR index in nondiabetic patients on peritoneal dialysis and its relationship 
with cardiovascular disease and mortality. Nefrologia. 2013;33(1):8592. https://doi.org/10.3265/nefrologia.pre2012.nov.11430.

26. Kramer H, Dugas $L$, Rosas SE. Race and the insulin resistance syndrome. Semin Nephrol. 2013;33(5):457-67. https://doi.org/10.1016/j.semne phrol.2013.07.007.

27. Kodama K, Tojjar D, Yamada S, Toda K, Patel CJ, Butte AJ. Ethnic differences in the relationship between insulin sensitivity and insulin response: a systematic review and meta-analysis. Diabetes Care. 2013;36(6):1789-96. https://doi.org/10.2337/dc12-1235.

28. Møller JB, Dalla Man C, Overgaard RV, Ingwersen SH, Tornøe CW, Pedersen $\mathrm{M}$, et al. Ethnic differences in insulin sensitivity, $\beta$-cell function, and hepatic extraction between Japanese and Caucasians: a minimal model analysis. J Clin Endocrinol Metab. 2014;99(11):4273-80. https://doi. org/10.1210/jc.2014-1724.
Ready to submit your research? Choose BMC and benefit from:

- fast, convenient online submission

- thorough peer review by experienced researchers in your field

- rapid publication on acceptance

- support for research data, including large and complex data types

- gold Open Access which fosters wider collaboration and increased citations

- maximum visibility for your research: over $100 \mathrm{M}$ website views per year

At BMC, research is always in progress.

Learn more biomedcentral.com/submissions 